OPEN ACCESS

Edited by:

Philippe Lepage,

Queen Fabiola Children's University

Hospital, Belgium

Reviewed by:

Arturo Solis-Moya

Dr. Carlos Sáenz Herrera National

Children's Hospital, Costa Rica

Nicolas Lefèvre,

Queen Fabiola Children's

University Hospital, Belgium

*Correspondence:

Hanneke Eyns

Hanneke.Eyns@uzbrussel.be orcid.org/0000-0001-9130-5528

${ }^{\dagger}$ Denis Piérard orcid.org/0000-0002-7756-3691

Elke De Wachter orcid.org/0000-0003-4070-1023

Peter Vaes orcid.org/0000-0001-5492-3079 Anne Malfroot orcid.org/0000-0002-7878-6715

Specialty section: This article was submitted to Pediatric Infectious Diseases,

a section of the journal

Frontiers in Pediatrics

Received: 29 March 2018 Accepted: 04 December 2018 Published: 18 December 2018

Citation:

Eyns $H$, Piérard D, De Wachter E Eeckhout $L$, Vaes $P$ and Malfroot $A$ (2018) Respiratory Bacterial Culture

Sampling in Expectorating and

Non-expectorating Patients With Cystic Fibrosis. Front. Pediatr. 6:403.

doi: 10.3389/fped.2018.00403

\section{Respiratory Bacterial Culture Sampling in Expectorating and Non-expectorating Patients With Cystic Fibrosis}

\author{
Hanneke Eyns ${ }^{1,2,3 *}$, Denis Piérard ${ }^{4 \dagger}$, Elke De Wachter ${ }^{1 \dagger}$, Leo Eeckhout ${ }^{4}$, Peter Vaes ${ }^{2,3+}$ and \\ Anne Malfroot ${ }^{1 \dagger}$ \\ ${ }^{1}$ Department of Pediatrics, Pediatric Pulmonology and Pediatric Infectious Diseases, Cystic Fibrosis Clinic, Universitair \\ Ziekenhuis Brussel, Vrije Universiteit Brussel, Brussels, Belgium, ${ }^{2}$ Department of Physical Medicine and Physiotherapy, \\ Universitair Ziekenhuis Brussel, Vrije Universiteit Brussel, Brussels, Belgium, ${ }^{3}$ Department of Physiotherapy, Human \\ Physiology and Anatomy, Faculty of Physical Education and Physiotherapy, Vrije Universiteit Brussel, Brussels, Belgium, \\ ${ }^{4}$ Department of Microbiology and Infection Control, Universitair Ziekenhuis Brussel, Vrije Universiteit Brussel, Brussels, \\ Belgium
}

Purpose: Different respiratory sampling methods exist to identify lower airway pathogens in patients with cystic fibrosis (CF), of which bronchoalveolar lavage (BAL), and expectorated sputum are considered the "gold standard." Because BAL cannot be repeated limitless, the diagnosis of lower respiratory tract infections in non-expectorating patients is challenging. Other sampling techniques are nasal swab, cough swab, and induced sputum. The purpose of this study (NCT02363764) was to compare concordance between the microbiological yield of nasal swab, cough swab, and expectorated sputum in expectorating patients; nasal swab, cough swab, and induced sputum in non-expectorating patients; nasal swab, cough swab, induced sputum, and BAL in patients requiring bronchoscopy ("BAL-group"); and to determine the clinical value of cough swab in non-expectorating patients with CF.

Methods: Microbiological yield detected by these different sampling techniques was compared between and within 105 expectorating patients, 30 non-expectorating patients and BAL-group $(n=39)$ in a single CF clinic. Specificity, sensitivity, positive (PPV), and negative (NPV) predictive values were calculated.

Results: Overall low sensitivity (6.3-58.0\%) and wide-ranging predictive values (0.0-100.0\%) indicated that nasal swab was not appropriate to detect lower airway pathogens [Pseudomonas aeruginosa $(\mathrm{Pa})$, Staphylococcus aureus (Sa), and Haemophilus influenzae $(H i)]$ in all three patient groups. Microbiological yield, specificity, sensitivity, PPV, and NPV of cough swab and induced sputum were largely similar in non-expectorating patients and in BAL-group (except sensitivity $(0.0 \%)$ of induced sputum for $\mathrm{Hi}$ in BAL-group). Calculations for $\mathrm{Pa}$ and $\mathrm{Hi}$ could not be performed for non-expectorating patients because of low prevalence ( $n=2$ and $n=3$, respectively). In expectorating patients, concordance was found between cough swab and expectorated sputum, except for Hi (sensitivity of 40.0\%). 
Conclusion: Our findings suggest that cough swab might be helpful in detecting the presence of some typical CF pathogens in the lower airways of clinically stable patients with CF. However, in symptomatic patients, who are unable to expectorate and who have a negative cough swab and induced sample, BAL should be performed as it currently remains the "gold standard."

Keywords: cystic fibrosis, respiratory samples, cough swab, sputum, bronchoalveolar lavage (BAL)

\section{INTRODUCTION}

The most important site of disease and the predominant cause of both morbidity and mortality in cystic fibrosis (CF) is the respiratory tract. Chronic infection results in a prolonged inflammatory response, which is believed to cause respiratory tissue injury leading to progressive loss of pulmonary function $(1,2)$. While Haemophilus influenzae $(H i)$ and Staphylococcus aureus $(\mathrm{S} a)$ may predominate early in life, $\sim 20 \%$ of children with $\mathrm{CF}$ aged $2-5$ years and $55-75 \%$ of adults with $\mathrm{CF}$ are chronically infected with Pseudomonas aeruginosa ( $\mathrm{Pa}$ ) (3). Certain bacteria, such as $P a$, are associated with a worse clinical outcome than others, but can be completely eradicated if identified early and treated promptly. There is sufficient evidence that eradication of early infection and prevention of chronic infection is associated with clinical benefit $(1,3,4)$. Therefore, accurate identification of lower respiratory tract pathogens is crucial in the management of $\mathrm{CF}$ and is recommended to be performed at least every 3 months using bacterial culture sampling $(2,5)$. Samples can be obtained through different methods of which bronchoalveolar lavage (BAL) is considered to be the "gold standard" method (6). Because BAL is an invasive method which cannot be repeated limitless, spontaneously expectorated sputum sample is accepted as second best (7). This, however, implies that the diagnosis of lower respiratory tract infections in the non-expectorating patient with CF can be challenging. Other methods (Table 1), such as induced sputum, cough swabs, throat swabs, and nasal swabs, have been developed to obtain bacterial cultures in these non-expectorating patients $(7-12)$. Studies investigating these different sampling methods, however, reported conflicting results (7-12).

Despite the available literature, questions about sampling methods used for respiratory bacterial cultures in the nonexpectorating patient with $\mathrm{CF}$ remain unanswered. Is the microbiological yield of nasal swab, cough swab, and expectorated or induced sputum the same for each sampling method, and in expectorating vs. non-expectorating patients? Are microbiological results of these techniques as sensitive and as specific as those of BAL? What is the clinical value of cough swab for the identification of bacterial pathogens in the lower airways of the non-expectorating patient with CF? The aim of this study is to answer these questions by comparing results for prevalence, sensitivity, specificity, positive, and negative predictive value of nasal swab, cough swab, and expectorated or induced sputum and BAL.
TABLE 1 | Definition of different sampling methods for bacterial cultures (7-12).

\begin{tabular}{|c|c|}
\hline Method & Definition \\
\hline Bronchoalveolar lavage & $\begin{array}{l}\text { Fluid squirted into and recollected from the } \\
\text { lungs during bronchoscopy }\end{array}$ \\
\hline Cough swab & $\begin{array}{l}\text { Swab placed into the posterior pharynx, } \\
\text { without direct contact with the oropharyngeal } \\
\text { mucosa, and asking the patient to cough }\end{array}$ \\
\hline $\begin{array}{l}\text { Induced cough swab or } \\
\text { Induced sputum sample }\end{array}$ & $\begin{array}{l}\text { Cough swab or sputum sample obtained } \\
\text { following inhalation of hypertonic saline }\end{array}$ \\
\hline Nasal suctioning & Suctioning of the nasal cavity \\
\hline Nasal swab & Swab of the nasopharyngeal wall \\
\hline Oropharyngeal suctioning & Suctioning of the oropharynx \\
\hline $\begin{array}{l}\text { Oropharyngeal swab or Throat } \\
\text { swab }\end{array}$ & Swab of the posterior oropharyngeal wall \\
\hline Expectorated sputum sample & Spontaneous expectoration of sputum \\
\hline
\end{tabular}

\section{METHODS}

\section{Participants}

Confirmed diagnosis of CF by sweat test and/or two identified CF-causing CFTR-mutations was mandatory for eligibility. All patients attending the Cystic Fibrosis Clinic of the Universitair Ziekenhuis (UZ) Brussel for their annual assessment or for a clinically indicated bronchoscopy between January 2015 and August 2016, were informed of the study by the specialized CF physiotherapist and invited to participate. Clinical indications for bronchoscopy were: persistent infection with clinical symptoms not improving despite antibiotic treatment and/or radiographic abnormalities such as newly acquired atelectasis not resolving with chest physiotherapy, anatomical abnormalities, external compression of the bronchi, etc.

The study protocol was approved by the Ethics Committee (O.G.16) of the UZ Brussel (B.U.N. 143201422976) and has been registered at ClinicalTrials.gov (NCT02363764). Parents, legal guardians, or of-age subjects provided written informed consent in accordance with the declaration of Helsinki prior to enrolment in this prospective study. Patients under the age of 18 were asked to provide assent consent.

\section{Sampling Procedures}

Baseline demographic data (Table 2) including age, gender, body mass index (BMI), lung function, and CF-causing CFTRmutation were obtained prior to sampling. 
TABLE 2 | Baseline demographic data.

\begin{tabular}{|c|c|c|c|c|}
\hline & Expectorating patients & Non-expectorating patients & BAL-group & Sign. \\
\hline$N$ & 105 & 30 & 39 & \\
\hline Children (018 years) $(n, \%)$ & $42(40.0 \%)$ & $29(96.7 \%)$ & $29(74.4 \%)$ & \\
\hline Adults ( $\geq 18$ years) $(n, \%)$ & $63(60.0 \%)$ & $1(3.3 \%)$ & $10(25.6 \%)$ & \\
\hline Gender, n male (\%) & $58(56.3 \%)$ & $18(61.1 \%)$ & 13 (33.3\%) & \\
\hline Age (mean, $\pm S D$ ) & $23.9( \pm 11.6)$ & $9.2( \pm 4.8)$ & $13.4( \pm 10.3)$ & $p=0.000$ \\
\hline $\mathrm{BMI}($ mean, $\pm S D$ ) & $20.2( \pm 3.4)$ & $16.7( \pm 2.8)$ & $17.4( \pm 3.3)$ & $p=0.000$ \\
\hline $\mathrm{FEV}_{1}$ (\%pred) (mean, $\pm S D$ ) & $70.8( \pm 24.8)$ & $94.4( \pm 13.9)$ & $63.1( \pm 25.5)$ & $p=0.000$ \\
\hline FVC (\%pred) (mean, $\pm S D$ ) & $86.0( \pm 18.0)$ & $95.9( \pm 12.1)$ & $77.7( \pm 23.4)$ & $p=0.004$ \\
\hline \multicolumn{5}{|l|}{ CF mutation } \\
\hline Homozygous F508del & 49 & 8 & 26 & \\
\hline Other mutations ${ }^{\mathrm{a}}$ & 56 & 22 & 13 & \\
\hline
\end{tabular}

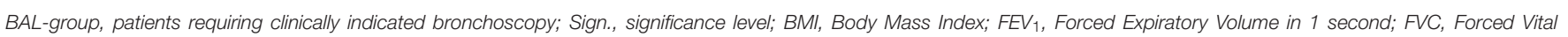
Capacity; ${ }^{a}$ Heterozygous F508del or Other/Other. Bold values indicates significant difference between the three groups..

Patients attending the CF Clinic for their annual assessment were divided into two groups depending on their ability to expectorate sputum on demand. From expectorating patients, a nasal swab, cough swab and spontaneously expectorated sputum, were obtained. From non-expectorating patients a nasal swab, cough swab, and induced sputum/cough swab were obtained. Patients attending the CF Clinic for a clinically indicated bronchoscopy (BAL-group) provided a nasal swab, cough swab, induced sample (all obtained by the CF physiotherapist), and BAL (obtained by the pulmonologist).

To avoid microbiological contamination of the samples, sequential samples were collected as described below:

- Nasal swab: The patient was seated on a chair or on the lap of his parent with the head tilted slightly backwards. The physiotherapist inserted the swab (regular size nylon flocked swab, eSwab ${ }^{\mathrm{TM}}$, Copan Diagnostics Inc., Brescia, Italy) gently through the left and right nostril, respectively, into the nasopharynx and swirled it back and forth. The swab was then removed from the nose and placed into the accompanying tube filled with $1 \mathrm{ml}$ of liquid Amies to send to the laboratory.

- Cough swab: After mouth-rinsing with water to avoid contamination from the nasopharynx the patient was assisted by the physiotherapist during a 10-min airway clearance session [autogenic drainage (AD)]. Subsequently, a swab was placed into the oropharynx without touching the pharyngeal mucosa and the patient was instructed to cough onto the swab (regular size nylon flocked swab, eSwab ${ }^{\mathrm{TM}}$, Copan Diagnostics Inc., Brescia, Italy). If a participant was too young to understand the instruction, a cough reflex was used to make the subject cough. The swab was then removed from the oropharynx and placed into the accompanying tube filled with $1 \mathrm{ml}$ of liquid Amies to send to the laboratory.

- Expectorated sputum: The patient rinsed his mouth a second time and was asked to cough and expectorate his sputum into a sterile container.

- Induced sputum/cough swab: If the patient was unable to expectorate sputum on demand after obtaining the cough swab he was asked to inhale $4 \mathrm{ml}$ of hypertonic saline ("HS", $\mathrm{NaCl} 6 \%$ ) nebulized by the patient's own device (Pari Boy (SX) or eFlow Rapid, PARI GmbH, Starnberg, Germany) after premedication (10-min delay) with salbutamol (100 $\mu \mathrm{g}$ via metered dose inhaler + spacer). The subject was then encouraged to cough and expectorate his sputum into a sterile container. If the patient was still unable to expectorate sputum a second cough swab was obtained by the physiotherapist following the method as explained previously but without another airway clearance session.

Nasal swab, cough swab, and induced sputum/cough swab were obtained within the hour prior to bronchoscopy, but before sedation. All subjects were monitored transcutaneous for oxygen saturation and heart rate $\left(\right.$ Nellcor $^{\mathrm{TM}} \mathrm{N}-600 \mathrm{X}$ with OxiMax ${ }^{\mathrm{TM}}$, Medtronic, Minneapolis, USA) and received supplementary oxygen as needed. The flexible fiber bronchoscope (Olympus BS XP160S 2.8, BS 3C160 3.8, 1T180 6.4, Olympus Europa SE\&CO. $\mathrm{KG}$, Hamburg, Germany) was always (both in children and adults) inserted orally to avoid nasal contamination. In addition, use of the suction channel was avoided until the tip of the bronchoscope passed the carina. A BAL-sample was collected by the pulmonologist during bronchoscopy as follows: aliquots of $0.5 \mathrm{ml} / \mathrm{kg}$ per lobe (total max. $=100 \mathrm{ml}$ ) of isotonic saline warmed to body temperature $\left(36.5^{\circ} \mathrm{C}\right)$ were instilled and then recollected by mechanical suction in an aseptic disposable for examination. Pediatric patients were sedated according to age and weight. Children under 8 months and/or $6 \mathrm{~kg}$ received atropine intrarectally and tetracaine $1 \%$ in $\mathrm{NaCl} 0.9 \%$ in the nose $(2 \mathrm{ml})$ and pharynx $(\max .6 \mathrm{ml})$. Children over 8 months and $6 \mathrm{~kg}$ were sedated with $0.6 \mathrm{ml} / \mathrm{kg}$ midazolam $(5 \mathrm{mg} / \mathrm{ml}$; max. $1.5 \mathrm{ml}), 0.6 \mathrm{ml} / \mathrm{kg}$ atropine $(0.25 \mathrm{mg} / \mathrm{ml}$; max. $1 \mathrm{ml}), 0.02$ $\mathrm{ml} / \mathrm{kg}$ tramadol hydrochloride $(50 \mathrm{mg} / \mathrm{ml}$, max. $0.6 \mathrm{ml})$, and tetracaine $1 \%$ in $\mathrm{NaCl} 0.9 \%$ in the nose $(2 \mathrm{ml})$ and pharynx (max. $6 \mathrm{ml}$ ). In adult patients only topical anesthesia was applied to the pharynx (lidocaine hydrochloride 10\%; three sprays with a 5 -min interval) and vocal cords $(0.8 \mathrm{ml}$ lidocaine hydrochloride $2 \%$ ). 


\section{Microbiological Analyses}

All samples were sent to the laboratory within $1 \mathrm{~h}$, stored at $4^{\circ} \mathrm{C}$ and processed within $24 \mathrm{~h}$ (13). Sample specimens were inoculated onto horse blood agar supplemented with $\mathrm{X}$ and $\mathrm{V}$ factors and vancomycin, bacitracin and clindamycin, mannitol salt agar, MacConkey agar, and Burkholderia cepacia selective agar for isolation of organisms associated with CF lung disease: $\mathrm{Pa}, \mathrm{Sa}, \mathrm{Hi}$, Burkholderia species, Streptococcus pneumoniae, Enterobacteriaceae, and other non-glucose fermenting Gram negative organisms. Isolated colonies were identified by MALDITOF mass spectrometry and antibiotic susceptibility testing was performed by disc diffusion.

\section{Data Analyses}

Based on the study by Equi et al. who obtained CS from 161 patients and compared these to expectorated sputum in a subgroup of 30 patients, we calculated that sample size had to be at least 114 patients for the initial sampling study, if a 5\% margin of error and 95\% confidence intervals were considered (10). To take a $15 \%$ loss of data into account (e.g., patients denying participation, patients not tolerating HS-inhalation, loss of samples, etc.), sample size was increased to 134 subjects.

Continuous variables (age, BMI, $\mathrm{FEV}_{1}$ \%pred, FVC) were compared using ANOVA and post-hoc Bonferroni. Differences between groups (expectorating patients, non-expectorating patients and BAL-group) and within groups (each sample method) were calculated from $3 \times 2$ - or $4 \times 2$-tables. Bonferronicorrection was applied where needed. Sensitivity, specificity and positive (PPV) and negative (NPV) predictive values, with corresponding 95\% binomial confidence intervals (95\% CI) were calculated from $2 \times 2$-tables if $n \geq 5(9,14)$. Expectorated sputum, cough swab and BAL were used as the reference sample in the expectorating patients, non-expectorating patients and BAL-group, respectively.

Statistical analyses were performed using SPSS Statistical Software Version 25 for Windows (IBM, Armonk, NY, USA). For all analyses, unless stated otherwise, $p<0.05$ was considered to be significant.

\section{RESULTS}

\section{Descriptive Data}

After including 135 of the eligible 170 patients attending our CF clinic, thereby achieving the predetermined sample size, further inclusion was ended. Thirty participants required the inhalation of hypertonic saline to induce sputum (=non-expectorating patients), the other 105 were able to expectorate sputum on demand (=expectorating patients). During the study period, 40 patients underwent clinically indicated bronchoscopy (=BALgroup). Because one BAL-sample was lost, the remainder 39 subjects were included in the analyses.

Baseline demographic data are described in Table 2. Fifty-five percent $(n=58)$ of the expectorating patients, $60 \%(n=18)$ of the non-expectorating patients and $33.3 \%(n=13)$ of the BALgroup were male. Expectorating patients [mean $( \pm S D)$ age: 23.9 $( \pm 11.6)$ years] were significantly older than non-expectorating patients [9.2 ( \pm 4.8$)$ years] and patients in the BAL-group [13.4
$( \pm 10.3)$ years] $(\boldsymbol{p}=\mathbf{0 . 0 0 0})$. Non-expectorating patients had a significantly higher $\mathrm{FEV}_{1} \%$ pred $(\boldsymbol{p}=\mathbf{0 . 0 0 0})$ and $\mathrm{FVC} \%$ pred $(\boldsymbol{p}=\mathbf{0 . 0 0 4})$ compared to expectorating patients and subjects who underwent bronchoscopy.

\section{Microbiological Analyses}

In total, 544 respiratory samples were obtained: 174 nasal swabs, 174 cough swabs, 52 induced sputum/cough swabs, 105 spontaneously expectorated sputum samples, and 39 BALs. Figure 1 shows the prevalence of $\mathrm{Pa}, \mathrm{Sa}, \mathrm{Hi}$, and "other Gramorganisms" (defined in Table 3 ) isolated from the respiratory samples in each group.

\section{Microbiological Prevalence Between Groups}

$\mathrm{Pa}$ was significantly more prevalent in expectorating patients $(42.0 \%)$ and subjects in the BAL-group $(35.9 \%)$ compared to non-expectorating patients $(6.7 \%)(\boldsymbol{p}=\mathbf{0 . 0 0 2})$. No difference was found between expectorating patients and BAL-subjects $(p=0.514$; Bonferroni- $p<0.017)$.

$\mathrm{Sa}$ was detected significantly more in expectorating patients $(65.7 \%)$ compared to non-expectorating patients $(56.7 \%)$ and patients who underwent bronchoscopy $(41.0 \%)(\boldsymbol{p}=\mathbf{0 . 0 1 0})$. $\mathrm{Sa}$-prevalence between non-expectorating patients and BALsubjects was not significantly different $(p=0.662$; Bonferroni$p<0.017)$.

Prevalence of $\mathrm{Hi}$ and other Gram-organisms, was not significantly different between groups $(p=0.972 ; p=0.125$, respectively).

\section{Microbiological Prevalence Within Groups Expectorating patients (Figure 1A)}

Overall microbiological yield of nasal swab, cough swab and expectorated sputum was significantly different between all methods $[\boldsymbol{p}=\mathbf{0 . 0 0 0}$; nasal swab vs. cough swab $(\boldsymbol{p}=\mathbf{0 . 0 0 0 *})$; cough swab vs. expectorated sputum $\left(\boldsymbol{p}=\mathbf{0 . 0 1 5 ^ { * }}\right)$; nasal swab vs. expectorated sputum $\left(\boldsymbol{p}=\mathbf{0 . 0 0 0}{ }^{*}\right)$ ( ${ }^{*}$ Bonferroni- $\left.p<0.017\right)$ ]. Prevalence of $\mathrm{Pa}, \mathrm{Sa}$, and other Gram-organisms in cough swab compared to expectorated sputum was not significantly different [37.1 vs. $42.0 \%\left(p=0.049^{*}\right) ; 63.8$ vs. $65.7 \%\left(p=0.616^{*}\right)$; and 22.3 vs. $28.6 \%\left(p=0.064^{*}\right)$ ( ${ }^{*}$ Bonferroni- $\left.p<0.017\right)$ ], whereas nasal swab yielded these pathogens significantly less compared to cough swab and expectorated sputum [all $\boldsymbol{p}=\mathbf{0 . 0 0 0}^{*}$ $\left({ }^{*}\right.$ Bonferroni- $\left.\left.p<0.017\right)\right]$. Hi was more prevalent in expectorated sputum (14.3\%) compared to nasal swab (3.8\%) and cough swab $(7.6 \%)(\boldsymbol{p}=\mathbf{0 . 0 0 1})$. Nasal swab and cough swab yielded $\mathrm{Hi}$ in the same range $(p=0.157$; Bonferroni- $p<0.017)$.

\section{Non-expectorating patients (Figure 1B)}

Overall microbiological yield was significantly different between nasal swab and cough swab $(\boldsymbol{p}=\mathbf{0 . 0 0 3}$; Bonferroni- $\boldsymbol{p}<0.017)$ and a trend toward a significant difference between nasal swab and induced sputum/cough swab was observed $(p=0.018$; Bonferroni- $p<0.017)$. Overall results for cough swab and induced sputum/cough swab were not significantly different $(p=0.542$; Bonferroni- $p<0.017)$. Prevalence of $\mathrm{Sa}$ and other Gram-organisms was only different in nasal swab compared to cough swab [33.3 vs. $56.7 \%$; $\boldsymbol{p}=\mathbf{0 . 0 1 2}$ and 10.8 vs. $32.4 \%$; 


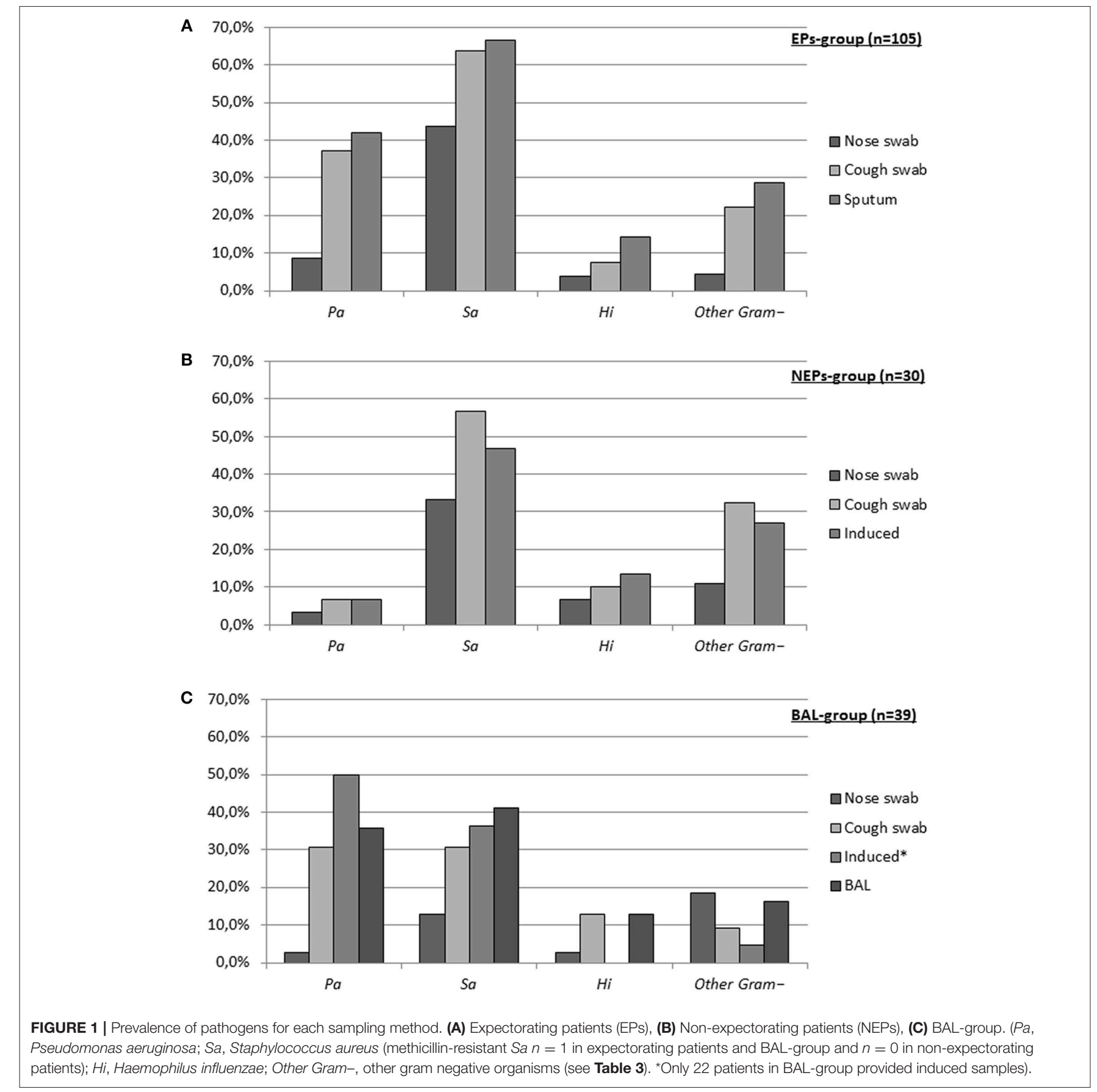

$\boldsymbol{p}=\mathbf{0 . 0 0 6}^{*}\left({ }^{*}\right.$ Bonferroni- $\left.\left.p<0.017\right)\right]$. Separate results for $\mathrm{Pa}$ and $H i$ could not be calculated as sample sizes were too small $(n=2$ and $n=3$, respectively).

\section{BAL-group (Figure 1C)}

Microbiological yield of cough swab, induced sputum/cough swab and BAL was similar overall, for $\mathrm{Pa}, \mathrm{Sa}$, and for other Gram- organisms. Nasal swab yielded significantly less CF specific pathogens compared to the other methods (all $\boldsymbol{p}=\mathbf{0 . 0 0 0}$; Bonferroni- $p<0.008$ ). Prevalence of $H i$ was too low $(n=6)$ to compare microbiological yield within the group.

\section{Sensitivity, Specificity, and Predictive Values}

Sensitivity, specificity, and predictive values are summarized in Table 4.

Nasal swab had low sensitivity (expectorating patients: 6.3-58.0\%; non-expectorating patients: $0.0-100.0 \%$; and BALgroup: $7.1-20.0 \%$ ) and high specificity (expectorating patients: 83.3-100.0\%; non-expectorating patients: 84.6-100.0\%; and 
TABLE 3 | Other Gram negative organisms.

\begin{tabular}{|c|c|c|c|}
\hline Organism & $\begin{array}{l}\text { Expectorating } \\
\text { patients }(n)\end{array}$ & $\begin{array}{c}\text { Non- } \\
\text { expectorating } \\
\text { patients }(n)\end{array}$ & $\begin{array}{l}\text { BAL-group } \\
\text { (n) }\end{array}$ \\
\hline Achromobacter species & 9 & 1 & - \\
\hline $\begin{array}{l}\text { Achromobacter } \\
\text { xylosoxidans }\end{array}$ & 1 & - & - \\
\hline Acinetobacter species & - & 2 & 1 \\
\hline Bordetella bronchiseptica & 1 & - & - \\
\hline Burkholderia cenocepacia & - & 1 & 1 \\
\hline Burkholderia multivorans & 3 & 1 & 1 \\
\hline Burkholderia vietnamiensis & 1 & - & - \\
\hline Elizabethkingia species & 1 & - & - \\
\hline $\begin{array}{l}\text { Enterobacter agglomerans } \\
\text { complex }\end{array}$ & 1 & - & - \\
\hline $\begin{array}{l}\text { Enterobacter cloacae } \\
\text { complex }\end{array}$ & 3 & 1 & - \\
\hline Escherichia coli & 3 & 1 & - \\
\hline Ewingella Americana & 1 & - & - \\
\hline Hafnia alvei & 1 & - & - \\
\hline Klebsiella pneumonia & - & - & 2 \\
\hline Klebsiella oxytoca & 1 & 2 & - \\
\hline Moraxella catarrhalis & 1 & 3 & 2 \\
\hline Ochrobactrum anthropic & - & - & 1 \\
\hline Ochrobactrum species & 1 & - & - \\
\hline Proteus mirabilis & 4 & - & 3 \\
\hline Pseudomonas putida & - & 1 & - \\
\hline Rhizobium radiobacter & - & 1 & 2 \\
\hline $\begin{array}{l}\text { Stenotrophomonas } \\
\text { maltophilia }\end{array}$ & 6 & 3 & 1 \\
\hline Total $n$ & 38 & 17 & 14 \\
\hline
\end{tabular}

BAL-group: 80.6-100.0\%) depending on the pathogen in all three patient groups compared to the reference sample (expectorated sputum, cough swab and BAL, respectively). In addition, wide ranging predictive values were observed in all three patient groups.

\section{Expectorating patients}

Sensitivity (86.7-89.9\%) and specificity (86.1-98.3\%) results of the cough swab were high for all pathogens, except the sensitivity for $\mathrm{Hi}(40.0 \%)$ and other Gram-organisms (66.7\%). Likewise, all predictive values were high for all pathogens (PPV:75.0-100.0\%; and NPV:81.6-90.8\%), except the PPV of other Gram-organisms (40.0\%).

\section{Non-expectorating patients}

In non-expectorating patients, sensitivity and specificity of induced sputum/cough swab were 76.7 and $92.3 \%$ for $S a$ and 80.0 and $84.6 \%$ for other Gram-organisms. PPV and NPV were high (75.0-92.9\%), except the PPV of other Gram-organisms (66.7\%). Results could not be calculated for $\mathrm{Pa}$ and $\mathrm{Hi}$ as prevalence of these pathogens was low ( $n=2$ and $n=3$, respectively).

\section{BAL-group}

Results for sensitivity, specificity and predictive values were all high $(>75.0 \%)$ and in the same range for cough swab and induced sputum/cough swab compared to BAL, except the sensitivity of $\mathrm{Hi}(80.0 \%$ in cough swab vs. $0.0 \%$ in induced sputum/cough swab) and the sensitivity of other Gram-organisms (42.9\% in cough swab vs. $66.7 \%$ in induced sputum/cough swab).

\section{DISCUSSION}

The present study investigated the accuracy of several respiratory sampling techniques for bacterial culture in patients with cystic fibrosis. In expectorating patients we examined nasal swab, cough swab and spontaneously expectorated sputum. Nasal swab and induced sputum were compared to cough swab in nonexpectorating subjects. In patients requiring a clinically indicated bronchoscopy, microbiological yield of nasal swab, cough swab, and induced sputum/cough swab was compared to the result of the bronchoalveolar lavage. Eventually, we wanted to find out whether the use of a cough swab is of clinical value in non-expectorating patients.

Sensitivity, specificity, and predictive values revealed that a nasal swab was not appropriate to detect pathogens present in the lower airways in all three patient groups (Table 4), which is also reflected in the prevalence chart (Figure 1). This finding confirms a previous study comparing nasal swab, throat swab, and sputum. A substantial difference was observed between nose microbiota on the one hand and microbiota from the throat and sputum on the other hand (15). A more recent study comparing 25 sets of nasopharyngeal, oropharyngeal (OP), and bronchoalveolar lavage suggested that the lungs of infants with CF have indeed their own microbiome which seems like, but is not identical to, the upper respiratory tract (16). Likewise, Taylor et al. compared nasal suctioning to cough swab (17). Although an equal prevalence of the most common bacteria $(\mathrm{Pa}, \mathrm{Sa}, \mathrm{Hi})$ was reported with both sampling techniques, the authors suggested that nasopharyngeal suctioning is not routinely warranted, because of the lack of benefit over throat swabs in detection of CF pathogens.

Despite a significantly different overall prevalence of pathogens in cough swab compared to sputum in expectorating patients, we did not find a significant difference when specifying for prevalence of $\mathrm{Pa}$ or $\mathrm{Sa}$. On the other hand, the high PPV and NPV for $P a$ and $S a$ are a positive finding. In other words, when $\mathrm{Pa}$ or $\mathrm{Sa}$ were detected in the cough swab of expectorating patients, the pathogen was most likely also isolated in the concomitantly obtained spontaneously expectorated sputum. Although avoiding oropharyngeal contamination, it is possible that expectorating patients coughed sputum onto the cough swab, thereby giving a higher quality specimen compared to nonexpectorating patients. Therefore, caution is warranted when extrapolating these results to the non-expectorating patients. Likewise, the findings in the BAL-group should be read carefully. Microbiological yield of cough swab and induced sputum was similar to that of BAL and was reflected by the high sensitivity, specificity, and predictive values. These results are confirmed by some authors $(8-10,18,19)$, but partially refuted by others (7, 9, 11, 18-21). Indeed, Ramsey et al. found a high PPV of an OP culture yielding $\mathrm{Pa}(83 \%)$ or $\mathrm{Sa}(91 \%)$ compared to BAL. 
TABLE 4 | Overall sensitivity, specificity, positive, and negative predictive values (PPV and NPV) [95\% CI].

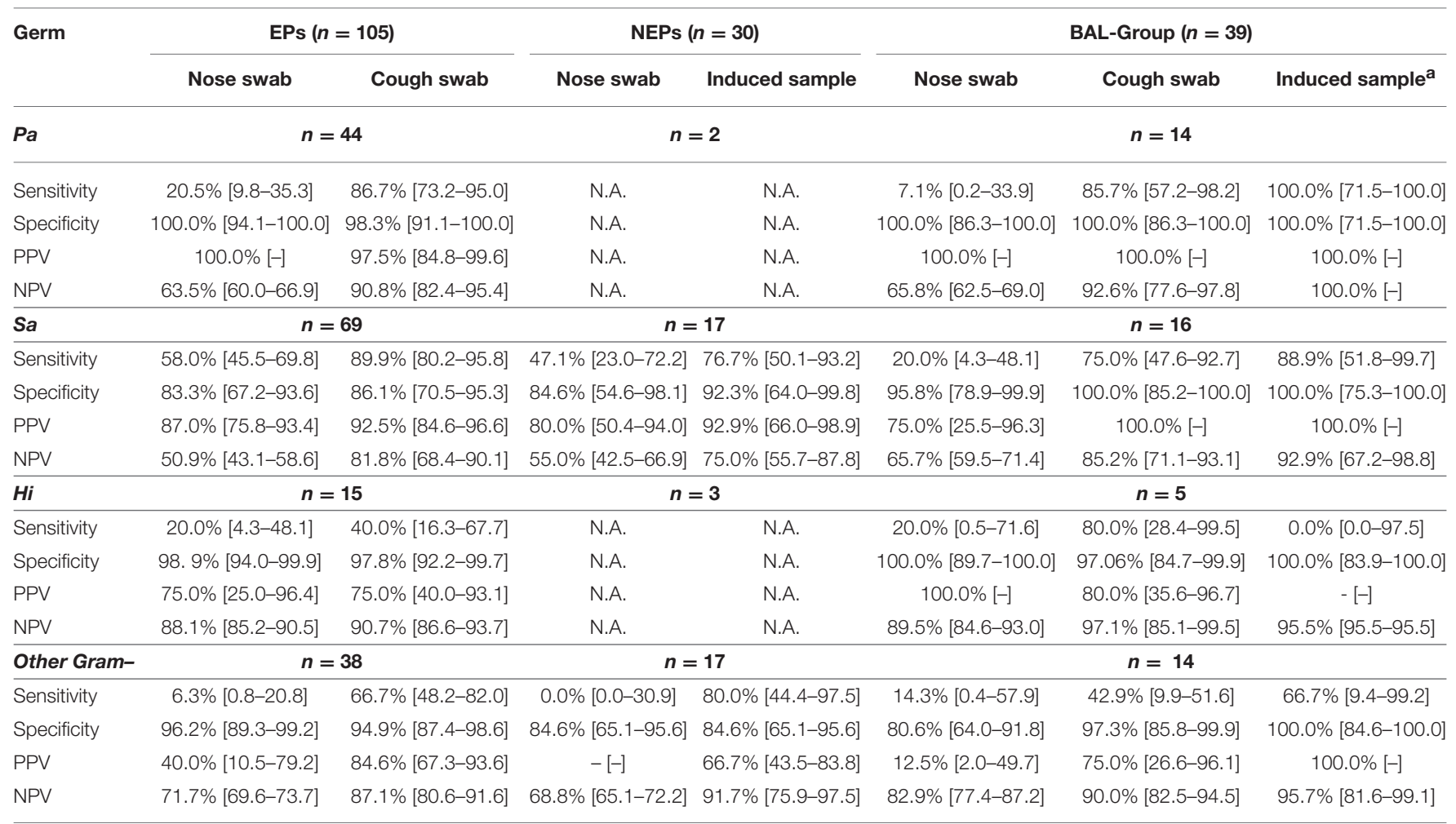

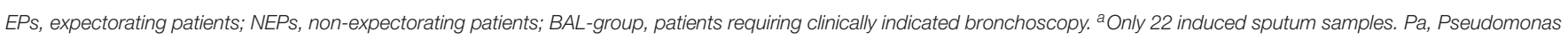
aeruginosa; N.A., not applicable (because of low sample size); Sa, Staphylococcus aureus; Hi, Haemophilus influenzae; Other Gram-, other gram negative organisms (see Table 3).

However, they also report lower NPVs $(<80 \%)$ as a result of a high frequency of false negatives. It is suggested that OP cultures yielding $P a$ and $S a$ are highly predictive of the presence of these pathogens in the lower airways of patients with CF, but a negative culture does not rule out their presence (8). This statement was supported by another study which reported a PPV of $100 \%$ and NPV of $21 \%$ for $\mathrm{Pa}$ (10). Contrary, other studies report low PPVs (41-69\%) and high NPVs (85-98\%) for OP cultures, meaning a negative culture is likely to rule out, but a positive culture does not "rule in" lower airway infection $(9,18,19,21)$.

Jung et al. evaluated throat swabs, spontaneous expectorated sputum and BAL from stable patients with CF for the detection of $\mathrm{Pa}$ (7). As confirmed by our results, sputum samples were found of equal value as samples obtained through bronchoscopy to detect $\mathrm{Pa}$ colonization. However, throat swabs were not suitable for characterizing bacterial conditions in participants' lower airways. A possible explanation is that cough swabs, as performed in our study, are less prone to upper airway contamination than throat swabs as used by Jung. In addition, our cough swab was obtained after a short airway clearance session, improving mucociliary clearance, and the upward movement of pathogens from the lower airways. It has been shown that the sensitivity of a throat swab after physiotherapy is higher compared to a normal throat swab (82-100 vs. 40-57\%) (22). Also, our patients required bronchoscopy on a clinical basis, unlike the patients in Jung's study. It has been demonstrated that yield and adequacy of samples is significantly higher in symptomatic children compared to those who are clinically stable (23), which might have influenced results in the BAL-group.

Studies assessing the clinical value of pre- and postinduction obtained sputum samples (after inhalation of HS) in non-expectorating patients, demonstrated an improved pathogen detection in the latter, which led to changes in patient management (11, 12, 20, 23-27). Additionally, a good bacteriologic correlation has been demonstrated between induced sputum samples and BAL in two smaller groups of symptomatic $(n=35)$ (12) and mixed (symptomatic and asymptomatic) patients with CF $(n=10)(28)$ and is confirmed by our results in the BAL-group. It has been suggested that in symptomatic patients sputum induction will correctly identify pathogens in the lower airways in most of these patients and should be performed and handled accordingly prior to bronchoscopy tailored treatment (12). On the other hand, an Australian group found that induced sputum compared to BAL, although not necessarily taken on the same day, in a larger group of patients with CF $(n=61)$ was not highly sensitive $(36.8 \%)$ or specific $(69.0 \%)$, with (50 and $60.9 \%$, respectively) or without (27.3 and $78.9 \%$, respectively) airway clearance (29). Therefore, it was concluded that the use of induced sputum should not be recommended in routine clinical practice (29). In addition, a recent study demonstrated a bactericidal effect of $\mathrm{HS}$ on $\mathrm{Pa}$ (30). As $P a$ is a typical CF-pathogen which is associated with 
reduced lung function and shortened life-expectancy in patients with CF (31), it is crucial to accurately detect an infection with this pathogen as early as possible.

The present study has several limitations. First, false-positive BAL cultures could be present among the results. Although the oral route was used to insert the bronchoscope and suctioning was avoided prior to wedging the scope in one lobe or the other, contamination by upper airway flora might have occurred and could have been avoided better by using a laryngeal mask. Secondly, BAL was not used as "gold standard" in all three patient groups. However, it should be noted that BAL has some limitations itself. Indeed, no consensus exists on how BAL should be performed, i.e., single-lobe, two-lobe, or comprehensive six-lobe BAL. Current guidelines recommend two-lobe BAL for children with CF (32). On the other hand, it has been demonstrated that six-lobe BAL is safe, well-tolerated and superior to single-lobe and two-lobe BAL, suggesting that bacterial communities might be heterogeneously spread throughout the airways (33). A most recent study wanted to account for "false" false positive results when comparing other sampling methods to BAL (12). Therefore, a "combined gold standard" was used, consisting of all pathogens identified by sputum induction and six-lobe BAL, as they presumed that pathogens isolated in sputum induction alone and not in BAL were rather additional lower airway pathogens instead of false positives. By using this "combined gold standard," six-lobe BAL and induced sputum alone were found to have a sensitivity of 81 and $63 \%$, respectively (12). This questions whether the use of BAL alone as "gold standard" is adequate when calculating sensitivity and specificity $(7-10,19,21,29)$, even when it is sixlobe BAL as was performed in our study. Thirdly, although in the same range of other similar studies (26-28), sample size of nonexpectorating patients is quite small, possibly resulting in a lower prevalence of some typical CF-pathogens. However, the low prevalence of $\mathrm{Pa}(n=2)$ and $\mathrm{Hi}(n=3)$ should not be attributed to younger age of non-expectorating patients compared to that of expectorating patients. Indeed, subjects in the BAL-group were also significantly younger than expectorating patients, but demonstrated similar rates of positive cultures. It should more likely be attributed to the fact that expectorating patients and patients in the BAL-group showed more signs of disease, reflected by a lower lung function, and thus, are more likely to be colonized with disease causing CF-pathogens. It has been demonstrated that yield and adequacy of samples is significantly higher in symptomatic children compared to those who are clinically stable (24). Fourthly, not all patients in the BAL-group (22 out of 39) provided an induced sample. This implies that prevalence of pathogens in induced samples might have been falsely higher than it really was. However, we found concordance in results of cough swab, induced sputum and BAL in these 22 patients. Lastly, if a patient was unable to expectorate sputum after HS-inhalation, we performed a second cough swab instead of OP suctioning because children do not tolerate OP suctioning very well $(21,29)$. Therefore, it is suggested that clinicians should consider patient age and the risk of increased anxiety if limited sensitivity of a sampling technique has been demonstrated (29).

With this study, we could not disprove the existing controversy with regard to respiratory culture sampling in the clinically stable non-expectorating patient with CF. However, for now, we will not change our current practice of using cough swab for bacterial culture to another sampling method in this patient group, because: (I) our results did not reveal a difference between cough swab and induced samples, whether or not compared to BAL, in both our non-expectorating patients (no results for $\mathrm{Pa}$ and $\mathrm{Hi}$ due to low prevalence) and BAL-group (except sensitivity for $\mathrm{Hi}$ ); (II) of the limited repeatability of bronchoscopy (7); (III) of the limited tolerability of OP suctioning, especially in children (29); (IV) of the known anti-Pa effect of HS which is used with sputum induction (30); and (V) sputum induction is timeconsuming (20-45 $\mathrm{min}$ ) and expensive $(24,28)$. Nonetheless, in symptomatic patients, sputum induction should be performed prior to BAL (12). Additionally, despite the fact that our nonexpectorating patients preferred the nasal swab as sampling method (34), we will not use nasal swab as sampling method because our results demonstrated that it was not appropriate to detect pathogens of the lower airways. Likewise, we will obtain spontaneously expectorated sputum from patients who are able to expectorate, because of the overall significant superiority compared to cough swab. In addition, this sampling technique was preferred over cough swab and nasal swab in expectorating patients (34).

Nevertheless, respiratory sampling in non-expectorating patients remains challenging. Therefore, it is important to continue the search for the best sampling technique that is repeatable, which is currently not the case for BAL. A study comparing microbiological yield and sensitivity, specificity and predictive values of normal cough swab, induced cough swab and induced $\mathrm{OP}$ suctioning to BAL in these nonexpectorating patients will be of great interest. In addition, it might be considered to include non-expectorating patients suffering from other chronic respiratory diseases, such as primary ciliary dyskinesia (PCD) and non-CF bronchiectasis. Like in patients with $\mathrm{CF}$, these patients require close surveillance in regard to respiratory bacterial growth (35-37). Typical CFpathogens, such as $\mathrm{Pa}, \mathrm{Sa}, \mathrm{Hi}$, and Streptococcus pneumoniae, are also predominant in the culture growths of patients with PCD and non-CF bronchiectasis. Furthermore, presence of $\mathrm{Pa}$ is associated with greater impairment in lung function, increased airway inflammation, more frequent exacerbations, worse quality of life, greater risk of hospitalization, and increased mortality (35-37). Treatment decisions, including the selection of antibiotics, are often tailored toward culture history and microbial sensitivity (37). Therefore, patients with PCD and non-CF bronchiectasis will also benefit from improved sampling techniques.

\section{CONCLUSION}

The present study investigated the accuracy of several respiratory sampling techniques for bacterial culture in patients with cystic fibrosis. Because of the lower microbiological yield, low sensitivity and the wide range in predictive values of nasal swab compared to the other methods, we conclude that nasal swab is not appropriate to detect pathogens present in the lower airways of these patients. Cough swab and induced sputum showed similar results for microbiological yield, specificity, 
sensitivity, and predictive values, both in non-expectorating patients (however, no results for $\mathrm{Pa}$ and $\mathrm{Hi}$ ) and patients undergoing clinically indicated bronchoscopy. Additionally, cough swab and induced sputum results were also similar to BAL, except for Hi (induced samples) and other Gram-organisms (both cough swab and induced samples). Our findings suggest that cough swab might be helpful in detecting the presence of some typical CF pathogens in the lower airways of clinically stable patients with CF. However, in symptomatic patients who are unable to expectorate and who have a negative cough swab and induced sample, BAL should be performed as it currently remains the "gold standard."

\section{DATA AVAILABILITY STATEMENT}

Data may compromise the privacy of study participants and may not be shared publicly. Data are available upon request to the corresponding author (HE).

\section{REFERENCES}

1. Cohen-Cymberknoh M, Shoseyov D, Kerem E. Managing cystic fibrosis: strategies that increase life expectancy and improve quality of life. Am J Respir Crit Care Med. (2011) 183:1463-71. doi: 10.1164/rccm.201009-1478CI

2. Smyth AR, Bell SC, Bojcin S, Bryon M, Duff A, Flume P, et al. European cystic fibrosis society standards of care: best practice guidelines. J Cyst Fibros. (2014) 13:S23-42. doi: 10.1016/j.jcf.2014.03.010

3. Gaspar MC, Couet W, Olivier JC, Pais AACC, Sousa JJS. Pseudomonas aeruginosa infection in cystic fibrosis lung disease and new perspectives of treatment: a review. Eur J Clin Microbiol Infect Dis. (2013) 32:1231-52. doi: 10.1007/s10096-013-1876-y

4. Clancy JP, Jain M. Personalized medicine in cystic fibrosis: dawning of a new era. Am J Respir Crit Care Med. (2012) 186:593-7. doi: 10.1164/rccm.201204-0785PP

5. Lahiri T, Hempstead SE, Brady C, Cannon CL, Clark K, Condren ME, et al. Clinical practice guidelines from the cystic fibrosis foundation for preschoolers with cystic fibrosis. Pediatrics (2016) 137:e20151784. doi: 10.1542/peds.2015-1784

6. Connett GJ. Bronchoalveolar lavage. Paediatr Respir Rev. (2000) 1:52-6. doi: 10.1053/prrv.2000.0007

7. Jung A, Kleinau I, Schönian G, Bauernfeind A, Chen C, Griese M, et al. Sequential genotyping of Pseudomonas aeruginosa from upper and lower airways of cystic fibrosis patients. Eur Respir J. (2002) 20:1457-63. doi: 10.1183/09031936.02.00268002

8. Ramsey BW, Wentz KR, Smith AL, Richardson M, Williams-Warren J, Hedges DL, et al. Predictive value of oropharyngeal cultures for identifying lower airway bacteria in cystic fibrosis patients. Am Rev Respir Dis. (1991) 144:331-7. doi: 10.1164/ajrccm/144.2.331

9. Rosenfeld M, Emerson J, Accurso F, Armstrong D, Castile R, Grimwood $\mathrm{K}$, et al. Diagnostic accuracy of oropharyngeal cultures in infants and young children with cystic fibrosis. Pediatr Pulmonol. (1999) 28:321-8. doi: 10.1002/(SICI)1099-0496(199911)28:5<321::AID-PPUL3>3.0.CO;2-V

10. Equi AC, Pike SE, Davies J, Bush A. Use of cough swabs in a cystic fibrosis clinic. Arch Dis Child. (2001) 85:438-9. doi: 10.1136/adc.85.5.438

11. Ho SA, Ball R, Morrison LJ, Brownlee KG, Conway SP. Clinical value of obtaining sputum and cough swab samples following inhaled hypertonic saline in children with cystic fibrosis. Pediatr Pulmonol. (2004) 38:82-7. doi: 10.1002/ppul.20035

12. Ronchetti K, Tame JD, Paisey C, Thia LP, Doull I, Howe R, et al. The CF-Sputum Induction Trial (CF-SPIT) to assess lower airway bacterial sampling in young children with cystic fibrosis: a prospective internally

\section{AUTHOR CONTRIBUTIONS}

HE drafted the manuscript. DP and LE completed the methods section (microbiological analyses). ED and AM completed the methods section (bronchoscopy protocol). DP, ED, LE, PV, and AM provided critical input to the rest of the manuscript, and all the authors approved the final version.

\section{FUNDING}

AM received an unrestricted scientific grant (BE1411267874) from Novartis Pharmaceutics nv for this study.

\section{ACKNOWLEDGMENTS}

The authors would like to thank all the patients and their parents/legal guardian attending the UZ Brussels' CF-clinic who gave consent to participate in the trial.

controlled interventional trial. Lancet Respir Med. (2018) 6:461-71. doi: 10.1016/S2213-2600(18)30171-1

13. Garcia L. Respiratory tract cultures (Chapter 3.11). In: Garcia L, editor. Clinical Microbiology Procedures Handbook, 3rd ed. Washington, DC: ASM Press (2010). p. 321-409.

14. Parikh R, Mathai A, Parikh S, Sekhar GC, Thomas R. Understanding and using sensitivity, specificity and predictive values. Indian J Opthalmol. (2008) 56:45-50. doi: 10.4103/0301-4738.37595

15. Boutin S, Graeber SY, Weitnauer M, Panitz J, Stahl M, Clausznitzer D, et al. Comparison of microbiomes from different niches of upper and lower airways in children and adolescents with cystic fibrosis. PLOS ONE (2015) 10:e0116029. doi: 10.1371/journal.pone.0116029

16. Prevaes SM, de Steenhuijsen Piters WA, de Winter-de Groot KM, Janssens HM, Tramps-Stranders GA, Chu ML, et al. Concordance between upper and lower airway microbiota in infants with cystic fibrosis. Eur Respir J. (2017) 49:1602235. doi: 10.1183/13993003.02235-2016

17. Taylor L, Corey M, Matlow A, Sweezey NB, Ratjen F. Comparison of throat swabs and nasopharyngeal suction specimens in non-sputum producing patients with cystic fibrosis. Pediatr Pulmonol. (2006) 41:839-43. doi: 10.1002/ppul.20451

18. Burns JL, Gibson RL, McNamara S, Yim D, Emerson J, Rosenfeld M, et al. Longitudinal assessment of Pseudomonas aeruginosa in young children with cystic fibrosis. J Infect Dis. (2001) 183:444-52. doi: 10.1086/318075

19. Armstrong DS, Grimwood K, Carlin JB, Carzino R, Olinsky A, Phelan PD. Bronchoalveolar lavage or oropharyngeal cultures to identify lower respiratory pathogens in infants with cystic fibrosis. Pediatr Pulmonol. (1996) 21:267-75. doi: 10.1002/(SICI)1099-0496(199605)21:5<267::AID-PPUL1>3.0.CO;2-K

20. Hoppe JE, Towler EE, Wagner BD, Accurso FJ, Sagel SD, Zemanick ET. Sputum induction improves detection of pathogens in children with cystic fibrosis. Pediatr Pulmonol. (2015) 50:638-46. doi: 10.1002/ppul.23150

21. Doumit M, Belessis Y, Stelzer-Braid S, Mallitt KA, Rawlinson W, Jaffe A. Diagnostic accuracy and distress associated with oropharyngeal suction in cystic fibrosis. J Cyst Fibros. (2016) 15:473-8. doi: 10.1016/j.jcf.2015. 09.001

22. Kabra SK, Alok A, Kapil A, Aggarwal G, Kabra M, Lodha R, et al. Can throat swab after physiotherapy replace sputum for identification of microbial pathogens in children with cystic fibrosis? Indian J Pediatr. (2004) 71:21-3. doi: 10.1007/BF02725650

23. Zampoli M, Pillay K, Carrara H, Zar HJ, Morrow B. Microbiological yield from induced sputum compared to oropharyngeal swab in young children with cystic fibrosis. J Cyst Fibros. (2016) 15:605-10. doi: 10.1016/j.jcf.2016.01.001 
24. Al-Saleh S, Dell SD, Grasemann H, Yau YCW, Waters V, Martin $\mathrm{S}$, et al. Sputum induction in routine clinical care of children with cystic fibrosis. J Pediatr. (2010) 157:1006-11. doi: 10.1016/j.jpeds.2010. 06.001

25. Zemanick ET, Wagner BD, Robertson CE, Stevens MJ, Szefler SJ, Accurso FJ, et al. Assessment of airway microbiota and inflammation in cystic fibrosis using multiple sampling methods. Ann Am Thorac Soc. (2015) 12:211-9. doi: 10.1513/AnnalsATS.201407-310OC

26. Aaron SD, Kottachchi D, Ferris WJ, Vandemheen KL, St Denis ML, Plouffe A, et al. Sputum versus bronchoscopy for diagnosis of Pseudomonas aeruginosa biofilms in cystic fibrosis. Eur Respir J. (2004) 24:631-7. doi: 10.1183/09031936.04.00049104

27. Henig NR, Tonelli MR, Pier MV, Burns JL, Aitken ML. Sputum induction as a research tool for sampling the airways of subjects with cystic fibrosis. Thorax (2001) 56:306-11. doi: 10.1136/thorax.56. 4.306

28. Blau H, Linnane B, Carzino R, Tannenbaum E-L, Skoric B, Robinson $\mathrm{PJ}$, et al. Induced sputum compared to bronchoalveolar lavage in young, non-expectorating cystic fibrosis children. J Cyst Fibros. (2014) 13:106-10. doi: 10.1016/j.jcf.2013.05.013

29. D'Sylva P, Caudri D, Shaw N, Turkovic L, Douglas T, Bew J, et al. Induced sputum to detect lung pathogens in young children with cystic fibrosis. Pediatr Pulmonol. (2017) 52:182-9. doi: 10.1002/ppul.23636

30. Michon AL, Jumas-Bilak E, Chiron R, Lamy B, Marchandin H. Advances toward the elucidation of hypertonic saline effects on Pseudomonas aeruginosa from cystic fibrosis patients. PLoS ONE (2014) 9:e90164. doi: 10.1371/journal.pone.0090164

31. Emerson J, Rosenfeld M, McNamara S, Ramsey BW, Gibson RL. Pseudomonas aeruginosa and other predictors of mortality and morbidity in young children with cystic fibrosis. Pediatr Pulmonol. (2002) 34:91-100. doi: $10.1002 /$ ppul.10127
32. Brennan S, Gangell C, Wainwright C, Sly PD. Disease surveillance using bronchoalveolar lavage. Paediatr Respir Rev. (2008) 9:151-9. doi: 10.1016/j.prrv.2008.01.002

33. Gilchrist FJ, Salamat S, Clayton S, Peach J, Alexander J, Lenney W. Bronchoalveolar lavage in children with cystic fibrosis: how many lobes should be sampled? Arch Dis Child. (2011) 96:215-7. doi: 10.1136/adc.2009.177618

34. Eyns H, De Wachter E, Malfroot A, Vaes P. Acute pain perception during different sampling methods for respiratory culture in cystic fibrosis patients. J Pain Symptom Manage. (2018) 55:872-80. doi: 10.1016/j.jpainsymman.2017.11.004

35. Mirra V, Werner C, Santamaria F. Primary Ciliary Dyskinesia: an update on clinical aspects, genetics, diagnosis, and future treatment strategies. Front Pediatr. (2017) 5:135. doi: 10.3389/fped.2017.00135

36. Pizzutto SJ, Hare KM, Upham JW. Bronchiectasis in children: current concepts in immunology and microbiology. Front Pediatr. (2017) 5:123. doi: 10.3389/fped.2017.00123

37. Polineni D, Davis SD, Dell SD. Treatment recommendations in primary ciliary dyskinesia. Pediatr Respir Rev. (2016) 18:39-45. doi: 10.1016/j.prrv.2015.10.002

Conflict of Interest Statement: The authors declare that the research was conducted in the absence of any commercial or financial relationships that could be construed as a potential conflict of interest.

Copyright (C) 2018 Eyns, Piérard, De Wachter, Eeckhout, Vaes and Malfroot. This is an open-access article distributed under the terms of the Creative Commons Attribution License (CC BY). The use, distribution or reproduction in other forums is permitted, provided the original author(s) and the copyright owner(s) are credited and that the original publication in this journal is cited, in accordance with accepted academic practice. No use, distribution or reproduction is permitted which does not comply with these terms. 